\title{
Antimicrobial Effects of Essential Oils for Multidrug-Resistant Acinetobacter baumanii
}

\author{
Chang-Eun Park ${ }^{1}$, Pil Seung Kwon ${ }^{2}$ \\ ${ }^{1}$ Department of Biomedical Laboratory Science, Molecular Diagnostics Research Institute, Namseoul University, Cheonan, Korea \\ ${ }^{2}$ Department of Clinical Laboratory Science, Wonkwang Health Science University, Iksan, Korea
}

\section{다제내성 아시네토박터 바우마니의 에센셜 오일에 대한 항균효과}

\author{
박창은 ${ }^{1}$, 권필승 ${ }^{2}$ \\ ${ }^{1}$ 남서울대학교 임상병리학과, 분자진단연구소, ${ }^{2}$ 원광보건대학교 임상병리과
}

\begin{abstract}
Acinetobacter baumanniiis categorized as a red alert pathogen that is increasingly associated with a high mortality rate in infected patients because of its resistance to extensive antibiotics. This study evaluated the antibacterial activities of some essential oils (tee tree, rosemary, and lavender oils) against 18 clinical isolates of multidrug-resistant $A$. baumannii(MRAB). The carbapenemase screening Hodge test showed that all 20 strains of $A$. baumannii were resistant to imipenem. The identification of multidrug-resistant microbes was carried out using the VITEK system. The antimicrobial activity of essential oils was tested by a disk diffusion method against MRAB. In the disk diffusion method, tea tree showed the largest increase in inhibition size compared to lavender oil, and rosemary had no antibacterial effect. These results proved the antimicrobial effect of multidrug resistance $A$. baumannii. Tee tree oil would be a useful alternative natural product for the treatment and prevention of most common human pathogens and MRAB infections. This is expected to be used as an antimicrobial agent, such as hand disinfectant using natural essential oil in the future.
\end{abstract}

Key words: Disk diffusion, Essential oils, Multidrug-resistant Acinetobacter baumannii, Tea tree

This is an Open Access article distributed under the terms of the Creative Commons Attribution Non-Commercial License (http://creativecommons.org/licenses/by-nc/4.0) which permits unrestricted non-commercial use, distribution, and reproduction in any medium, provided the original work is properly cited.

Copyright ( 2018 The Korean Society for Clinical Laboratory Science. All rights reserved.

\author{
Corresponding author: Pil Seung Kwon \\ Department of Clinical Laboratory Science, \\ Wonkwang Health Science University, 514 \\ Iksandae-ro, Iksan 54538, Korea \\ Tel: 82-63-840-1212 \\ Fax: 82-63-840-1219 \\ E-mail: pskwon@wu.ac.kr
}

Received: September 21, 2018

Revised: October 19, 2018

Accepted: October 26, 2018

\section{서 론}

에센셜 오일(essential oil)은 식물의 2차 대사산물 중 인체에 약리효과를 나타내는 성분으로 이루어진 휘발성 유기화합물 로, 주로 식물의 내분비선에서 분비되며 식물체내에서 생합성 되어 생성된다. 이들은 식물종이나 부위에 따라 여러 가지 향기 나특성이 다르고 수증기 증류법, 용매추출법, 압착법 등에 의해 추출한다. 오일은 수소, 탄소, 산소 등이 화학물질이 기본구조이 며 테르펜류, 에스테르, 알데하이드, 옥사이드, 케톤, 알콜 등의 다양한 성분과 함량이 존재한다[1]. 로즈마리(rosemary)는 Rosemarinus officinalis 학명으로 유럽에서 오랜 세월동안 기억을 증진시키기 위한 상징처럼 여 겨지며[2], 로즈마리 입은 항 인간면연결핍바이러스[3], 항염증 [4], 항종양[5]과 항산화[6]를 포함하여 다양한 생리활성인자에 관여하는 것으로 알려져 있다.

티트리(tee tree)는 Melaeuca alternifolia 학명으로 감염된 상처부위에 탁월한 효과가 있으며, 항균효과가 있다고 알려져 있다[7]. 라벤더(lavender)는 Lavandula angustifolia 학명으 로 여러 가지 용도로 사용되는 것으로 스트레스, 불면, 우울, 항 산화에 효과가 있다고 알려져 있다[8]. 최근 천연물질의 자연치 
유능력에 대한 관심도가 높아짐에 따라 식물에서 추출한 에센 셜 오일의 효과에 대한 연구가 활발히 진행되고 있다[9]. 따라서 이들의 항균력을 평가하고자 하였다. 최근 Acinetobacter baumanii는 폐렴, 폐혈증, 심내막염, 요로감염, 창상감염, 수막 염 등 다양한 유형의 감염증 등 주로 면역능이 저하된 환자에 감 염증을 유발하는 기회 감염균으로 중환자실 및 병원 환경에서 흔이 분리된다[10]. Acinetobacterspp.에 의한 감염으로 인하 여 발생하는 원내감염이 병원 내에서 발생하는 전체 원내감염 중 10-30\%의 비율을 차지하고 있어 세계적으로 문제가 되고 있 다[11].

또한광범위베타락탐아제 (extended-spectrum $\beta$-lactamase, $\mathrm{ESBL}), \mathrm{AmpC} \beta$-lactamase 등의 효소를 생성하는 다제내성 $A$. baumannii균(multidrug-resistant $A$. baumannii, MRAB)의 증가로 인해 카바페넴(carbapenem)의 사용량이 확대되어서 결과적으로 이 약제에 대한 내성 균주가 증가되기 시작하였다. Acinetobacterspp.의 colistin에 대한 내성률은 2002년에서 2006년까지 분리된 Acinetobacter spp.중에서는 $18.2 \%$ 가 colistin에 내성을 보였다[12].

이미페넴(imipenem) 내성 A. baumannii에 의한 균혈증의 사망률은 $57.5 \%$ 로 imipenem 감수성 A. baumannii에 의한 균 혈증의 $20 \%$ 에 비하여 높으며, 이는 균혈증 초기에 부적절한 항 생제 치료로 인한 결과일 것으로 설명하고 있다[13].

국내분리 세균의 내성률 조사에 의하면 A. baumannii의 carbapenem 내성률은 2001년 6\%에서 2004년에 17\%로 증가 하였고, 2007년 27\%로 현저한 증가세를 보였으며, 2011년 “국 내 종합병원을 대상으로 항생제 내성 모니터링” 에서는 $63 \%$ 의 내성률을 보였다[14]. 2012년, 질병관리본부 다제내성균 감염 관리 지침에 의하면 $\mathrm{MRAB}$ 는 carbapenem계, aminoglycoside 계, fluoroquinolones계 항균제에 모두 내성을 나타내는 $A$. baumannii 균으로 감염병의 예방 및 관리에 관한 법률에 지정 감염병으로 포함되어 있는 다제내성균이다[15].

따라서, 본 연구의 목적은 임상에서 분리된 다제내성 $A$. baumannii을 분리하여 일반적으로 시판되는 천연 에센셜 오일 인 라벤더(lavender), 티트리(tea tree), 로즈마리(rosemary) 3 종류의 항균 효과를 평가하여 천연 에센셜 오일이 내성에 대한 강한 저항성을 보고하고 이러한 장점을 활용하여 원내 감염균 으로 알려진 세균들에 대해 예방제로 선택될 수 있는 가능성을 찾고자 한다.

\section{재료 및 방법}

\section{1. 대상균주}

본 연구는 2013년 12월부터 2014년 2월까지 충남지역 일개 대학병원의 임상에서 분리된 A. baumannii 균주 20균주를 사 용하였고 S1부터 S20으로 순서대로 명명하였고, 이중 18 개의 MRAB균과 다제내성이 아닌 2개의 A. baumannii 균주를 대상 으로 하였다. 이 중 동일 환자에서 반복 분리된 균주는 수집대상 에서 제외하였다.

\section{2. 에센셜 오일}

일반적으로 시중에 시판되는 $\mathrm{D}$ 사 제품 중 티트리(tee tree), 로즈마리(rosemary), 라벤더(lavender) 3개의 제품을 사용하 여 평가에 이용하였다. 판매업체에서 제공받은 물질안전자료 에 따르면 모두 수증기증류법으로 추출된 오일이며, 공급회사 의 물질안전자료에 따라 실험을 하였다. 에센셜오일의 원산지 와 학명은 Table 1과 같다.

\section{3. 균주 동정 및 항균제 감수성시험}

임상검체로부터 분리 배양된 균주는 Vitek $2^{\circledR}$ automated instrument IDs ystem (bioMérieux, Marcyl'Etoile, France) 을 이용하여 세균동정과 항균제 최소억제농도를 확인하였다.

\section{Carbapenemase 선별 시험법(Hodge test)}

Carbapenemase 생성 균주를 Hodge 변법으로 선별하였다. 시험에 사용된 표준균주는 E. coli ATCC 25922로 균주 부유액 탁도를 McFarland No 0.5로 맞춘 후 MacConkey 한천에 면봉 으로 고루 접종한다. 접종 한 균주가 마른 뒤 배지의 중앙에 imipenem 디스크(10 $\mu \mathrm{g}, \mathrm{BBL}$, Cockeysville, MI, USA)를 놓 은 후, A. baumanif를 디스크로부터 평판의 가장자리로 한 줄로 굵게 접종하였다. 이후 $37^{\circ} \mathrm{C}$ 산소성 배양기에 18 시간 배양 후 시험균주 접종선 중앙쪽 말단부가 다른 부위에 비해서 더 넓게 증식되면 양성으로 판정하였고, 이는 carbapenem 분해 효소 가 있음을 뜻한다.

Table 1. List of essential oil used in assay

\begin{tabular}{ccc}
\hline Essential oil & \multicolumn{1}{c}{ Scientific name } & Origin \\
\hline Tea tree & Melaleuca alternifolia & Australia \\
Lavender & Lavandula angustifolia & France \\
Rosemary & Rosemarinus officinalis & India \\
\hline
\end{tabular}




\section{5. 에센셜오일의 디스크 확산법}

CLSI 가이드라인 M07-A10 [16]에 따라 대상균주를 Mueller-Hinton agar에 직접 제조하여 계대 한 후 $37^{\circ} \mathrm{C}$ 배양 기(Vision scientific, Daejeon, Korea)에서 18 24시간 동안 배양 한 후 집락을 취하여 Mueller-Hinton broth $2 \mathrm{~mL}$ 에 현탁 시킨 다음 $1.5 \times 10^{8} \mathrm{CFU} / \mathrm{mL}$ 가 되는 $0.5 \mathrm{MacFarland}$ 표준값 을 densicheck 탁도계(bioMerieux, Marcy L'Etoile, France) 로 측정 한 후 Mueller-Hinton agar 에 멸균된 면봉으로 고루 분주 하였다. 각각의 허브오일 3종류를 멸균된 $6 \mathrm{~mm}$ 종이디스 크를 멸균된 petridish에 세 개씩 담은 다음 일반적으로 시판되 는 $\mathrm{D}$ 사의 에센셜 오일을 각 $10 \mu \mathrm{L}$ 씩 분주한 뒤 15 분간 흡수시킨 후 또 $10 \mu \mathrm{L}$ 씩 분주한 후 1시간을 건조시킨 후 Mueller-Hinton agar에 멸균된 핀셋으로 가볍게 올려놓은 후 살짝 눌러준 후 배 지 뚜껑을 밑으로 하여 산소성 배양기에서 $35^{\circ} \mathrm{C}$ 로 $18 \sim 24$ 시간 배양을 하였다. 이때 negative control로 mineral oil를 사용하 였다. 배양 후 디스크 주위의 억제대 직경 $(\mathrm{mm})$ 을 측정하였다. 이와 같은 실험은 4회 반복 시행하여 평균을 내었다.

\section{결 과}

\section{1. 검체별 특성}

임상에서 검체의 종류는 sputum 7건, urine 4건, urine culture 3건, open pus 3건, BAL (bronchoalveolar lavage) 2 건, blood 1건의 순서로 분리 되었다(Table 2).

\section{2. 항균제 감수성 검사}

항균제 감수성에서 carbapenem계의 항균제인 imipenem, meropenem에서 20개 균주 모두 내성을 확인하였고, colistin 은 모두 감수성을 확인하였다. Cephalosporin계는 3 세대 항균 제인 cefotaxime, ceftazidime와 4세대 cefepime, monobactam 계인 aztreonam, ampicillin/sulbactam(AMP/S), trimethoprim/ sulfamethoxazole (SXT), penicillin계는 3세대인 piperacillin 모두 내성을 나타냈다.

반면, aminoglycoside계의 gentamicin은 carbapenem 내 성을 보인 20 개 균 중 18 개 균은 내성, 2 개 균은 감수성을 보였 고, tetracycline계인 minocycline은 감수성이 11 균, 8 균이 중 간 내성인 반면, tigecycline은 $100 \%$ 감수성을 보였다. fluoroquinolone계인 ciprofloxacin은 모두 내성이지만, 새로 운 quinolone계 항생제인 levofloxacin은 내성이 19건, 중간 내성이 1 건 이었다. 이 결과로 질병관리본부 다제내성균 감염관
리 지침에 의해 다제내성에 부합하는 균은 gentamicin에 감수 성을 보인 1 번과 3 번 균주를 제외한 18 개 균주가 다제내성균으 로 판정되었다(Table 3).

\section{Carbapenemase 선별시험법}

Imipenem-Hodge 변법 시험을 시행하여 imipenem 내성 이 $\beta$-lactamase 생성에 의한 것인지 검사하였고, 그 결과는 20 개 균 모두 양성을 보여 carbapenem계에 내성이 있는 것으로 확인되었다(Figure 1).

\section{4. 에센셜오일의 항균효과}

티트리(tee tree)의 항균효과는 검체 중 $\mathrm{S} 18$ 번 검체가 $23 \mathrm{~mm}$ 의 억제대를 보여 가장 효과가 좋았으며, 평균값은 $19.6 \mathrm{~mm}$ 로 나타났다. 라벤더(lavender)에서는 S17번에서 $18.5 \mathrm{~mm}$ 의 억 제대를 보여 가장 효과가 좋았으며, 평균값은 $10.9 \mathrm{~mm}$ 로 평균 값이 나왔지만, tee tree 보다는 항균효과 낮은 것으로 나타났 다. 로즈마리(rosemary)는 항균효과가 아주 미미한 것으로 보 이며 $\mathrm{S} 1$ 과 $\mathrm{S} 17$ 번이 $8.5 \mathrm{~mm}$ 억제대를 보여 작은 억제대 범위를 보였고 그다음이 S3 번균이 $8 \mathrm{~mm}$ 로 나왔고, 나머지 균들은 거 의 항균효과가 없는 것으로 나타났다(Figure 2). 천연 에센셜 오

Table 2. General characteristics of clinical specimens

\begin{tabular}{cccc}
\hline No. of Sample & Analysis time (hrs) & Ward & Specimens \\
\hline S1 & 7.5 & GS & Open pus \\
S2 & 4.75 & PS & Open pus \\
S3 & 7 & IP & Sputum \\
S4 & 4.75 & IP & Blood \\
S5 & 7.75 & IP & Sputum \\
S6 & 7.75 & PS & Open pus \\
S7 & 8 & NR & Sputum \\
S8 & 7.75 & CS & Sputum \\
S9 & 7.5 & CS & Urine \\
S10 & 7.5 & ER & Sputum \\
S11 & 7.5 & IM & BAL \\
S12 & 10.5 & ER & Urine \\
S13 & 8.25 & NS & UC \\
S14 & 8 & NS & Urine \\
S15 & 9 & IP & BAL \\
S16 & 8.25 & UR & UC \\
S17 & 9.25 & DR & Sputum \\
S18 & 8.5 & IP & Urine \\
S19 & 9 & GS & Sputum \\
S20 & 8.25 & UR & UC \\
\hline
\end{tabular}

Abbreviations: BAL, bronchoalveolar lavage; UC, urine catheter; GS, general surgery; PS, plastic surgery; IP, internal pediatrics; $N R$, nursery room; CS, chest surgery; ER, emergency room; UR, urology; DR, dermatology; NS, neuro surgery; IM, internal medicine. 
Table 3. Antimicrobial susceptibility results of $A$. baumannii

\begin{tabular}{|c|c|c|c|c|c|c|c|c|c|c|c|c|c|c|c|}
\hline \multirow{2}{*}{ Isolate } & \multicolumn{15}{|c|}{ Antimicrobial MIC (interpretation) Units: $\mu \mathrm{g} / \mathrm{mL}$} \\
\hline & AMP/S & PIP & CEP & CFZ & CEF & $\mathrm{AZT}$ & IMP & MEM & GM & CIP & LEVO & MIN & TIG & $\mathrm{COL}$ & SXT \\
\hline S1 & $\begin{array}{c}\geq 32 \\
(R)\end{array}$ & $\begin{array}{c}\geq 128 \\
(R)\end{array}$ & $\begin{array}{c}\geq 64 \\
(R)\end{array}$ & $\begin{array}{c}\geq 64 \\
(R)\end{array}$ & $\begin{array}{c}\geq 64 \\
(R)\end{array}$ & $\begin{array}{c}\geq 64 \\
(R)\end{array}$ & $\begin{array}{c}\geq 16 \\
(R)\end{array}$ & $\begin{array}{l}\geq 16 \\
(R)\end{array}$ & $\begin{array}{c}2 \\
(\mathrm{~S})\end{array}$ & $\begin{array}{l}\geq 4 \\
(R)\end{array}$ & $\begin{array}{l}\geq 8 \\
(R)\end{array}$ & $\begin{array}{c}4 \\
(S)\end{array}$ & $\begin{array}{c}1 \\
\text { (S) }\end{array}$ & $\begin{array}{c}\leq 0.5 \\
(\mathrm{~S})\end{array}$ & $\begin{array}{c}\geq 320 \\
(R)\end{array}$ \\
\hline S2 & $\begin{array}{c}\geq 32 \\
(R)\end{array}$ & $\begin{array}{c}\geq 128 \\
(R)\end{array}$ & $\begin{array}{l}\geq 64 \\
(R)\end{array}$ & $\begin{array}{l}\geq 64 \\
(R)\end{array}$ & $\begin{array}{l}\geq 64 \\
(R)\end{array}$ & $\begin{array}{c}\geq 64 \\
(R)\end{array}$ & $\begin{array}{l}\geq 16 \\
(R)\end{array}$ & $\begin{array}{l}\geq 16 \\
(R)\end{array}$ & $\begin{array}{l}\geq 16 \\
(R)\end{array}$ & $\begin{array}{l}\geq 4 \\
(R)\end{array}$ & $\begin{array}{l}\geq 8 \\
(R)\end{array}$ & $\begin{array}{c}4 \\
(S)\end{array}$ & $\begin{array}{c}1 \\
(\mathrm{~S})\end{array}$ & $\begin{array}{c}\leq 0.5 \\
\text { (S) }\end{array}$ & $\begin{array}{c}\geq 320 \\
(R)\end{array}$ \\
\hline S3 & $\begin{array}{c}\geq 32 \\
(R)\end{array}$ & $\begin{array}{c}\geq 128 \\
(R)\end{array}$ & $\begin{array}{l}\geq 64 \\
(\mathrm{R})\end{array}$ & $\begin{array}{l}\geq 64 \\
(R)\end{array}$ & $\begin{array}{l}\geq 64 \\
(R)\end{array}$ & $\begin{array}{c}\geq 64 \\
(R)\end{array}$ & $\begin{array}{l}\geq 16 \\
(R)\end{array}$ & $\begin{array}{l}\geq 16 \\
(R)\end{array}$ & $\begin{array}{l}\leq 1 \\
(\mathrm{~S})\end{array}$ & $\begin{array}{l}\geq 4 \\
\text { (R) }\end{array}$ & $\begin{array}{l}\geq 8 \\
(R)\end{array}$ & $\begin{array}{l}\leq 1 \\
(\mathrm{~S})\end{array}$ & $\begin{array}{c}1 \\
\text { (S) }\end{array}$ & $\begin{array}{c}\leq 0.5 \\
(S)\end{array}$ & $\begin{array}{l}\geq 20 \\
(\mathrm{~S})\end{array}$ \\
\hline S4 & $\begin{array}{c}\geq 32 \\
(R)\end{array}$ & $\begin{array}{c}\geq 128 \\
(R)\end{array}$ & $\begin{array}{l}\geq 64 \\
(R)\end{array}$ & $\begin{array}{l}\geq 64 \\
(R)\end{array}$ & $\begin{array}{c}\geq 64 \\
(R)\end{array}$ & $\begin{array}{c}\geq 64 \\
(R)\end{array}$ & $\begin{array}{l}\geq 16 \\
(R)\end{array}$ & $\begin{array}{l}\geq 16 \\
(R)\end{array}$ & $\begin{array}{l}\geq 16 \\
(R)\end{array}$ & $\begin{array}{l}\geq 4 \\
\text { (R) }\end{array}$ & $\begin{array}{l}\geq 8 \\
(\mathrm{R})\end{array}$ & $\begin{array}{c}4 \\
(S)\end{array}$ & $\begin{array}{c}1 \\
\text { (S) }\end{array}$ & $\begin{array}{c}\leq 0.5 \\
(S)\end{array}$ & $\begin{array}{l}\geq 20 \\
\text { (S) }\end{array}$ \\
\hline S5 & $\begin{array}{l}16 \\
(\mathrm{I})\end{array}$ & $\begin{array}{c}\geq 128 \\
(\mathrm{R})\end{array}$ & $\begin{array}{c}\geq 64 \\
(R)\end{array}$ & $\begin{array}{c}\geq 64 \\
(\mathrm{R})\end{array}$ & $\begin{array}{l}32 \\
(R)\end{array}$ & $\begin{array}{c}\geq 64 \\
(R)\end{array}$ & $\begin{array}{c}\geq 16 \\
(R)\end{array}$ & $\begin{array}{l}\geq 16 \\
(R)\end{array}$ & $\begin{array}{c}\geq 16 \\
(R)\end{array}$ & $\begin{array}{l}\geq 4 \\
\text { (R) }\end{array}$ & $\begin{array}{l}\geq 8 \\
(R)\end{array}$ & $\begin{array}{l}8 \\
(\mathrm{I})\end{array}$ & $\begin{array}{c}2 \\
(\mathrm{~S})\end{array}$ & $\begin{array}{c}\leq 0.5 \\
(S)\end{array}$ & $\begin{array}{c}\geq 20 \\
(S)\end{array}$ \\
\hline S6 & $\begin{array}{c}\geq 32 \\
(\mathrm{R})\end{array}$ & $\begin{array}{c}\geq 128 \\
(\mathrm{R})\end{array}$ & $\begin{array}{c}\geq 64 \\
(\mathrm{R})\end{array}$ & $\begin{array}{c}\geq 64 \\
(\mathrm{R})\end{array}$ & $\begin{array}{c}\geq 64 \\
(\mathrm{R})\end{array}$ & $\begin{array}{c}\geq 64 \\
(R)\end{array}$ & $\begin{array}{c}\geq 16 \\
(R)\end{array}$ & $\begin{array}{c}\geq 16 \\
(R)\end{array}$ & $\begin{array}{c}\geq 16 \\
(\mathrm{R})\end{array}$ & $\begin{array}{l}\geq 4 \\
\text { (R) }\end{array}$ & $\begin{array}{l}\geq 8 \\
(R)\end{array}$ & $\begin{array}{c}4 \\
(S)\end{array}$ & $\begin{array}{c}1 \\
\text { (S) }\end{array}$ & $\begin{array}{c}\leq 0.5 \\
(\mathrm{~S})\end{array}$ & $\begin{array}{c}\geq 320 \\
(R)\end{array}$ \\
\hline S7 & $\begin{array}{l}\geq 32 \\
(R)\end{array}$ & $\begin{array}{c}\geq 128 \\
(R)\end{array}$ & $\begin{array}{l}\geq 64 \\
(R)\end{array}$ & $\begin{array}{l}\geq 64 \\
(\mathrm{R})\end{array}$ & $\begin{array}{l}\geq 64 \\
(R)\end{array}$ & $\begin{array}{c}\geq 64 \\
(R)\end{array}$ & $\begin{array}{l}\geq 16 \\
(R)\end{array}$ & $\begin{array}{l}\geq 16 \\
(R)\end{array}$ & $\begin{array}{l}\geq 16 \\
(R)\end{array}$ & $\begin{array}{l}\geq 4 \\
\text { (R) }\end{array}$ & $\begin{array}{l}\geq 8 \\
(\mathrm{R})\end{array}$ & $\begin{array}{l}8 \\
\text { (I) }\end{array}$ & $\begin{array}{c}1 \\
\text { (S) }\end{array}$ & $\begin{array}{c}\leq 0.5 \\
(S)\end{array}$ & $\begin{array}{c}\geq 320 \\
(R)\end{array}$ \\
\hline S8 & $\begin{array}{c}\geq 32 \\
(R)\end{array}$ & $\begin{array}{c}\geq 128 \\
(R)\end{array}$ & $\begin{array}{l}\geq 64 \\
(R)\end{array}$ & $\begin{array}{c}\geq 64 \\
(R)\end{array}$ & $\begin{array}{l}\geq 64 \\
(R)\end{array}$ & $\begin{array}{c}\geq 64 \\
(R)\end{array}$ & $\begin{array}{l}\geq 16 \\
(R)\end{array}$ & $\begin{array}{l}\geq 16 \\
(R)\end{array}$ & $\begin{array}{l}\geq 16 \\
(R)\end{array}$ & $\begin{array}{l}\geq 4 \\
\text { (R) }\end{array}$ & $\begin{array}{l}\geq 8 \\
(\mathrm{R})\end{array}$ & $\begin{array}{l}8 \\
(1)\end{array}$ & $\begin{array}{c}1 \\
\text { (S) }\end{array}$ & $\begin{array}{l}\leq 0.5 \\
\text { (S) }\end{array}$ & $\begin{array}{c}\geq 320 \\
(R)\end{array}$ \\
\hline S9 & $\begin{array}{c}\geq 32 \\
(\mathrm{R})\end{array}$ & $\begin{array}{c}\geq 128 \\
(\mathrm{R})\end{array}$ & $\begin{array}{c}\geq 64 \\
(\mathrm{R})\end{array}$ & $\begin{array}{c}\geq 64 \\
(R)\end{array}$ & $\begin{array}{c}\geq 64 \\
(R)\end{array}$ & $\begin{array}{c}\geq 64 \\
(R)\end{array}$ & $\begin{array}{l}\geq 16 \\
(R)\end{array}$ & $\begin{array}{l}\geq 16 \\
(R)\end{array}$ & $\begin{array}{l}\geq 16 \\
(\mathrm{R})\end{array}$ & $\begin{array}{l}\geq 4 \\
\text { (R) }\end{array}$ & $\begin{array}{l}\geq 8 \\
\text { (R) }\end{array}$ & $\begin{array}{c}4 \\
(S)\end{array}$ & $\begin{array}{c}1 \\
\text { (S) }\end{array}$ & $\begin{array}{c}\leq 0.5 \\
(S)\end{array}$ & $\begin{array}{c}\geq 320 \\
\text { (R) }\end{array}$ \\
\hline S10 & $\begin{array}{c}\geq 32 \\
(R)\end{array}$ & $\begin{array}{c}\geq 128 \\
(R)\end{array}$ & $\begin{array}{c}\geq 64 \\
(R)\end{array}$ & $\begin{array}{c}\geq 64 \\
(R)\end{array}$ & $\begin{array}{c}\geq 64 \\
(R)\end{array}$ & $\begin{array}{c}\geq 64 \\
(R)\end{array}$ & $\begin{array}{c}\geq 16 \\
(R)\end{array}$ & $\begin{array}{l}\geq 16 \\
(R)\end{array}$ & $\begin{array}{c}\geq 16 \\
(R)\end{array}$ & $\begin{array}{l}\geq 4 \\
(R)\end{array}$ & $\begin{array}{l}\geq 8 \\
(R)\end{array}$ & $\begin{array}{l}8 \\
(I)\end{array}$ & $\begin{array}{c}2 \\
(\mathrm{~S})\end{array}$ & $\begin{array}{c}\leq 0.5 \\
(\mathrm{~S})\end{array}$ & $\begin{array}{c}\geq 320 \\
(R)\end{array}$ \\
\hline S11 & $\begin{array}{c}\geq 32 \\
(\mathrm{R})\end{array}$ & $\begin{array}{c}\geq 128 \\
(\mathrm{R})\end{array}$ & $\begin{array}{c}\geq 64 \\
(\mathrm{R})\end{array}$ & $\begin{array}{c}\geq 64 \\
(\mathrm{R})\end{array}$ & $\begin{array}{c}\geq 64 \\
(\mathrm{R})\end{array}$ & $\begin{array}{c}\geq 64 \\
(R)\end{array}$ & $\begin{array}{c}\geq 16 \\
(R)\end{array}$ & $\begin{array}{c}\geq 16 \\
(R)\end{array}$ & $\begin{array}{c}\geq 16 \\
(\mathrm{R})\end{array}$ & $\begin{array}{l}\geq 4 \\
\text { (R) }\end{array}$ & $\begin{array}{l}\geq 8 \\
\text { (R) }\end{array}$ & $\begin{array}{c}4 \\
(\mathrm{~S})\end{array}$ & $\begin{array}{c}1 \\
\text { (S) }\end{array}$ & $\begin{array}{c}\leq 0.5 \\
\text { (S) }\end{array}$ & $\begin{array}{c}\geq 320 \\
(R)\end{array}$ \\
\hline S12 & $\begin{array}{l}\geq 32 \\
(\mathrm{R})\end{array}$ & $\begin{array}{c}\geq 128 \\
(R)\end{array}$ & $\begin{array}{l}\geq 64 \\
(R)\end{array}$ & $\begin{array}{l}\geq 64 \\
(R)\end{array}$ & $\begin{array}{l}\geq 64 \\
(R)\end{array}$ & $\begin{array}{l}\geq 64 \\
(R)\end{array}$ & $\begin{array}{l}\geq 16 \\
(R)\end{array}$ & $\begin{array}{l}\geq 16 \\
(R)\end{array}$ & $\begin{array}{l}\geq 16 \\
(R)\end{array}$ & $\begin{array}{l}\geq 4 \\
\text { (R) }\end{array}$ & $\begin{array}{l}\geq 8 \\
(R)\end{array}$ & $\begin{array}{l}\leq 1 \\
(\mathrm{~S})\end{array}$ & $\begin{array}{c}2 \\
(\mathrm{~S})\end{array}$ & $\begin{array}{c}\leq 0.5 \\
\text { (S) }\end{array}$ & $\begin{array}{l}160 \\
(R)\end{array}$ \\
\hline S13 & $\begin{array}{c}\geq 32 \\
(R)\end{array}$ & $\begin{array}{c}\geq 128 \\
(\mathrm{R})\end{array}$ & $\begin{array}{c}\geq 64 \\
(R)\end{array}$ & $\begin{array}{c}\geq 64 \\
(R)\end{array}$ & $\begin{array}{c}\geq 64 \\
(R)\end{array}$ & $\begin{array}{c}\geq 64 \\
(R)\end{array}$ & $\begin{array}{c}\geq 16 \\
(R)\end{array}$ & $\begin{array}{l}\geq 16 \\
(R)\end{array}$ & $\begin{array}{c}\geq 16 \\
(R)\end{array}$ & $\begin{array}{l}\geq 4 \\
(R)\end{array}$ & $\begin{array}{l}\geq 8 \\
(R)\end{array}$ & $\begin{array}{l}4 \\
(1)\end{array}$ & $\begin{array}{c}1 \\
\text { (S) }\end{array}$ & $\begin{array}{c}\leq 0.5 \\
\text { (S) }\end{array}$ & $\begin{array}{c}\geq 320 \\
(R)\end{array}$ \\
\hline S14 & $\begin{array}{c}\geq 32 \\
(R)\end{array}$ & $\begin{array}{c}\geq 128 \\
(R)\end{array}$ & $\begin{array}{c}\geq 64 \\
(R)\end{array}$ & $\begin{array}{l}\geq 64 \\
(R)\end{array}$ & $\begin{array}{c}\geq 64 \\
(R)\end{array}$ & $\begin{array}{c}\geq 64 \\
(R)\end{array}$ & $\begin{array}{l}\geq 16 \\
(R)\end{array}$ & $\begin{array}{l}\geq 16 \\
(R)\end{array}$ & $\begin{array}{l}\geq 16 \\
(R)\end{array}$ & $\begin{array}{l}\geq 4 \\
(R)\end{array}$ & $\begin{array}{l}\geq 8 \\
(\mathrm{R})\end{array}$ & $\begin{array}{l}8 \\
(1)\end{array}$ & $\begin{array}{c}2 \\
(\mathrm{~S})\end{array}$ & $\begin{array}{c}\leq 0.5 \\
(S)\end{array}$ & $\begin{array}{c}\geq 320 \\
(R)\end{array}$ \\
\hline S15 & $\begin{array}{l}16 \\
(\mathrm{I})\end{array}$ & $\begin{array}{c}\geq 128 \\
(R)\end{array}$ & $\begin{array}{l}\geq 64 \\
(\mathrm{R})\end{array}$ & $\begin{array}{l}\geq 64 \\
(R)\end{array}$ & $\begin{array}{l}\geq 64 \\
(R)\end{array}$ & $\begin{array}{c}\geq 64 \\
(R)\end{array}$ & $\begin{array}{l}\geq 16 \\
(R)\end{array}$ & $\begin{array}{l}\geq 16 \\
(R)\end{array}$ & $\begin{array}{l}\geq 16 \\
(R)\end{array}$ & $\begin{array}{l}\geq 4 \\
(R)\end{array}$ & $\begin{array}{l}\geq 8 \\
(R)\end{array}$ & $\begin{array}{l}\leq 1 \\
(\mathrm{~S})\end{array}$ & $\begin{array}{l}\geq 8 \\
(\mathrm{R})\end{array}$ & $\begin{array}{c}\leq 0.5 \\
(S)\end{array}$ & $\begin{array}{c}\geq 320 \\
(R)\end{array}$ \\
\hline S16 & $\begin{array}{c}\geq 32 \\
(R)\end{array}$ & $\begin{array}{c}\geq 128 \\
(R)\end{array}$ & $\begin{array}{c}\geq 64 \\
(\mathrm{R})\end{array}$ & $\begin{array}{c}\geq 64 \\
(R)\end{array}$ & $\begin{array}{c}\geq 64 \\
(R)\end{array}$ & $\begin{array}{c}\geq 64 \\
(R)\end{array}$ & $\begin{array}{l}\geq 16 \\
(R)\end{array}$ & $\begin{array}{l}\geq 16 \\
(R)\end{array}$ & $\begin{array}{l}\geq 16 \\
(R)\end{array}$ & $\begin{array}{l}\geq 4 \\
\text { (R) }\end{array}$ & $\begin{array}{l}\geq 8 \\
(R)\end{array}$ & $\begin{array}{l}\leq 1 \\
(\mathrm{~S})\end{array}$ & $\begin{array}{c}2 \\
\text { (S) }\end{array}$ & $\begin{array}{l}\leq 0.5 \\
\text { (S) }\end{array}$ & $\begin{array}{c}\geq 320 \\
(R)\end{array}$ \\
\hline S17 & $\begin{array}{c}\geq 32 \\
(\mathrm{R})\end{array}$ & $\begin{array}{c}\geq 128 \\
(\mathrm{R})\end{array}$ & $\begin{array}{c}\geq 64 \\
(\mathrm{R})\end{array}$ & $\begin{array}{c}\geq 64 \\
(\mathrm{R})\end{array}$ & $\begin{array}{c}\geq 64 \\
(\mathrm{R})\end{array}$ & $\begin{array}{c}\geq 64 \\
(R)\end{array}$ & $\begin{array}{c}\geq 16 \\
(R)\end{array}$ & $\begin{array}{l}\geq 16 \\
(\mathrm{R})\end{array}$ & $\begin{array}{c}\geq 16 \\
(R)\end{array}$ & $\begin{array}{l}\geq 4 \\
(R)\end{array}$ & $\begin{array}{l}\geq 8 \\
(\mathrm{R})\end{array}$ & $\begin{array}{l}8 \\
(1)\end{array}$ & $\begin{array}{c}1 \\
\text { (S) }\end{array}$ & $\begin{array}{c}\leq 0.5 \\
\text { (S) }\end{array}$ & $\begin{array}{l}160 \\
(R)\end{array}$ \\
\hline S18 & $\begin{array}{c}\geq 32 \\
(R)\end{array}$ & $\begin{array}{c}\geq 128 \\
(\mathrm{R})\end{array}$ & $\begin{array}{c}\geq 64 \\
(\mathrm{R})\end{array}$ & $\begin{array}{c}\geq 64 \\
(R)\end{array}$ & $\begin{array}{c}\geq 64 \\
(R)\end{array}$ & $\begin{array}{c}\geq 64 \\
(R)\end{array}$ & $\begin{array}{c}\geq 16 \\
(R)\end{array}$ & $\begin{array}{c}\geq 16 \\
(R)\end{array}$ & $\begin{array}{c}\geq 16 \\
(R)\end{array}$ & $\begin{array}{l}\geq 4 \\
(R)\end{array}$ & $\begin{array}{l}\geq 8 \\
\text { (R) }\end{array}$ & $\begin{array}{c}8 \\
(I)\end{array}$ & $\begin{array}{c}1 \\
\text { (S) }\end{array}$ & $\begin{array}{c}\leq 0.5 \\
(\mathrm{~S})\end{array}$ & $\begin{array}{c}\geq 320 \\
(R)\end{array}$ \\
\hline S19 & $\begin{array}{c}\geq 32 \\
(R)\end{array}$ & $\begin{array}{c}\geq 128 \\
(R)\end{array}$ & $\begin{array}{l}\geq 64 \\
(\mathrm{R})\end{array}$ & $\begin{array}{c}\geq 64 \\
(R)\end{array}$ & $\begin{array}{l}\geq 64 \\
(R)\end{array}$ & $\begin{array}{c}\geq 64 \\
(R)\end{array}$ & $\begin{array}{l}\geq 16 \\
(R)\end{array}$ & $\begin{array}{l}\geq 16 \\
(R)\end{array}$ & $\begin{array}{l}\geq 16 \\
(R)\end{array}$ & $\begin{array}{l}\geq 4 \\
(R)\end{array}$ & $\begin{array}{l}4 \\
(\mathrm{I})\end{array}$ & $\begin{array}{l}\leq 1 \\
(\mathrm{~S})\end{array}$ & $\begin{array}{c}1 \\
\text { (S) }\end{array}$ & $\begin{array}{l}\leq 0.5 \\
\text { (S) }\end{array}$ & $\begin{array}{l}160 \\
(R)\end{array}$ \\
\hline S20 & $\begin{array}{c}\geq 32 \\
(R)\end{array}$ & $\begin{array}{c}\geq 128 \\
(R)\end{array}$ & $\begin{array}{l}\geq 64 \\
(R)\end{array}$ & $\begin{array}{l}\geq 64 \\
(R)\end{array}$ & $\begin{array}{c}\geq 64 \\
(R)\end{array}$ & $\begin{array}{c}\geq 64 \\
(R)\end{array}$ & $\begin{array}{l}\geq 16 \\
(R)\end{array}$ & $\begin{array}{l}\geq 16 \\
(R)\end{array}$ & $\begin{array}{l}\geq 16 \\
(R)\end{array}$ & $\begin{array}{l}\geq 4 \\
(R)\end{array}$ & $\begin{array}{l}\geq 8 \\
(R)\end{array}$ & $\begin{array}{l}8 \\
(\mathrm{I})\end{array}$ & $\begin{array}{c}1 \\
\text { (S) }\end{array}$ & $\begin{array}{l}\leq 0.5 \\
\text { (S) }\end{array}$ & $\begin{array}{l}320 \\
(R)\end{array}$ \\
\hline
\end{tabular}

Abbreviations: AMP/S, Ampicillin/Sulbactam); PIP, Piperacillin; CEP, Cefotaxime; CFZ, Cefrazidime; CEF, Cefepime; AZT, Aztreonam; IMP, Imipenem; MEM, Meropenem; GM, Genamicin; CIP, Ciprofloxacin; COL, Colistin; LEVO, Levofloxacin; MIN, Minocycline; TIG, Tigecycline; SXT, Trimethoprim/Sulfamethoxazol.

일 3종중에 S1 번 균부터 S20 번 균주 모두 tee tree에 대해서는 가장 우수한 항균효과를 나타내었지만, Rosemary는 항균력을 발휘하지 못하였고, Lavender 역시 S17 번 균종에 대해서는 항 균력이 좋았지만, 나머지 균에 대해는 항균효과가 뛰어나지는 않았다(Figure 3). CLSI 가이드라인 M100[17] 정도관리판정기 준을 참조하면 ciprofloxacin, imipenem이 $21 \mathrm{~mm}, 22 \mathrm{~mm}$ 이상이면 감수성으로 판정하는 것으로 티트리의 평균값 19.6 $\mathrm{mm}$ 는 항균효과가 비슷한 것으로 추정된다.

\section{고 찰}

항균성이 알려진 천연물질로는 주로 lysozyme, polylysine, protamine, conalbumun, avidin,유기산, polyphenol 물질 등이 대표적이다[18-22]. Tee tree의 학명은 Malaleuca 


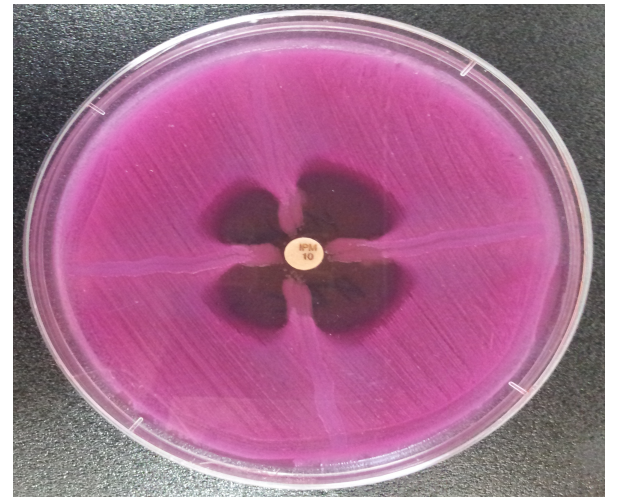

Figure 1. Image of hodge test with positive reaction for $A$. baummanii producing carbapenemase.

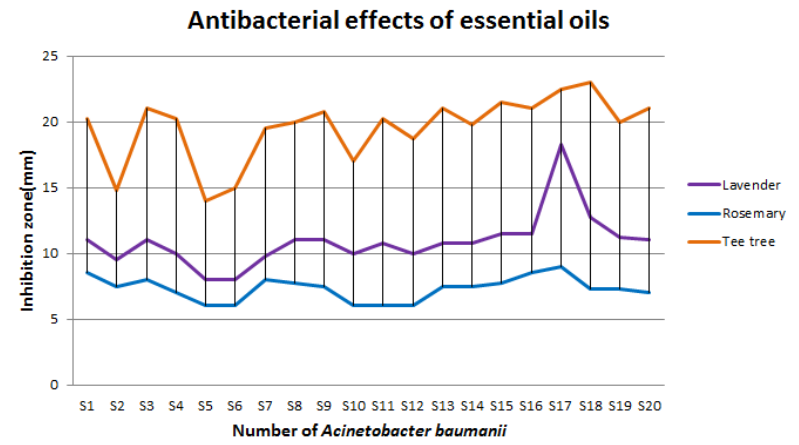

Figure 2. Antibacterial inhibition zone of essential oils against $A$. baumanii by disk diffusion method.

alternifolia로서 100여종의 다른 물질들로 구성되어 있는 복합 물이며, 항미생물작용의 terpinene-4-ol이 주성분이다[23]. 그리고 Shin 등[23]의 연구에 의하면 tee tree의 주요성분으로 는 4-terpineolol 35.22\%, $\alpha$-terpinene이 10.73\%, $\gamma$ terpinene이 19.63\%로 분석되었으나, 본 연구에 사용된 에센 셜오일은 판매처에서 제공받은 분석결과에 의하면 4-terpineol 은 라이브러리에 제외되었지만 $\alpha$-terpinene이 $28.1 \% \gamma$ terpinene이 $26.57 \%$ 로 테르펜 성분이 가장 높은 것으로 분석 되었다.

Aminoglycoside계 항균제에 감수성으로 나온 S1과 S3균 이 다제내성균이 아니지만, MRAB와 비교하여 보면 비슷한 항균효과가 보여 다제내성과의 에센셜오일의 항균력과는 연 관성이 없는 것으로 분석되었다. 2011년 Sienkiewicz 등[24] 은 임상검체에서 분리된 Staphylococcus, Enterococcus, Escherichia, Pseudomonas 균속을 대상으로 lavender oil 과 thyme oil의 항균활성을 비교하였는데 thyme oil은 Staphylococcus, Enterococcus, Escherichia에 대한 항균효 과가 좋았지만, lavender oil은 항균효과가 미비함을 보고하였

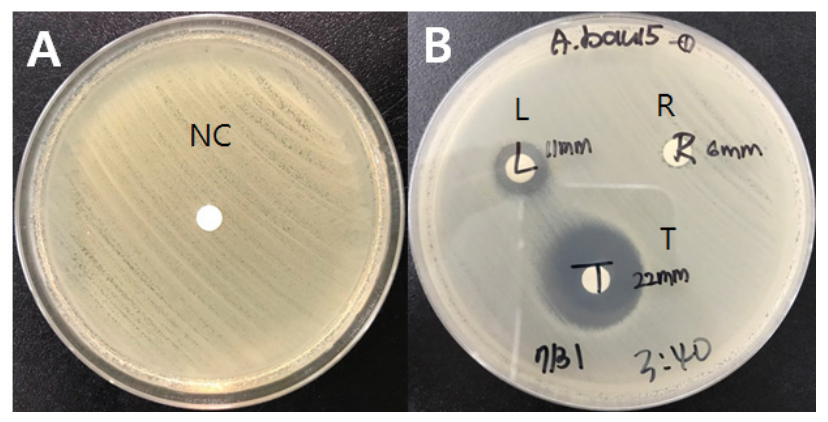

Figure 3. Antibacterial inhibition zone image of essential oils against $A$. baumanii by disk diffusion method. (A) NC, negative control (mineral oil), (B) T (tee tree); L (lavender); R (rosemary).

고, Pseudomonas 균속에 대해서 lavender oil과 thyme oil 모 두 좋지 않은 결과로 나왔다. 이는 우리의 연구에서도 대상균주 는 다르지만, tee tree에 비해 lavender가 항균효과가 떨어지는 것이 비슷하였다. 그 이유로는 허브 에센셜오일에 포함된 항균 효과를 나타내는 terpinene과 같은 항균성분을 가진 2차 대사 산물의 함량이 다르기 때문일 것으로 추정된다. 본 연구에서 S17균의 경우 lavender 오일에서 다른 균에 비해 항균효과가 뛰어난 것으로 조사되었는데 이에 대해서는 성분분석과 다양한 원인분석이 필요할 것으로 사료된다.

2014년 Mohaddese 등[25]은 임상에서 분리된 $A$. baumannii 균 32종을 대상으로 Oliveria decumbens, Pelargonium graveolens, Eugenia caryophyllata, Ziziphora tenuir, Trachyspermum copticum oils의 항균력을 평가하였 는데, O. decumbens와 E. caryophyllata, 그리고 T. copticum oils이 가장 효과적인 것으로 조사되었는데 그것은 thymol과 eugenol 성분이 함유된 페놀화합물 때문에 효과적인 항균력을 발휘한 것으로 보고되었다. 위의 연구의 디스크 확산법에서 $O$. decumbens과 E. caryophyllata, 그리고 T. copticum oils의 항균제 억제대가 $19.78 \mathrm{~mm}, 13.3 \mathrm{~mm}, 18 \mathrm{~mm}$ 로 보고되어, 본 연구의 tee tree oil의 결과인, 평균 $19.6 \mathrm{~mm}$ 억제대 범위와 비 슷한 항균력을 보여 결과적으로 tee tree oil은 O. decumbens 와 비슷한 항균력을 발휘하는 것으로 추정된다. 에센셜 오일의 항균 활성은 2004년 Nguefack 등[26]에 의하면 그람 음성균의 세포막의 침투성 증가와 ATP 감소로 lipopolysacharide (LPS) 방출로 사멸하거나 2009년 Bouhdid 등[27]은 칼륨의 유출로 세포손상이 오고 세포벽의 구조와 성분의 변화가 사멸을 유도 한다고 알려져 있으나 앞으로 좀 더 많은 에센셜오일의 살균 메 커니즘에 관한 연구가 필요하다고 사료된다.

시료의 추출방법에서도 시판되는 에센셜오일은 수증기 증류 법으로 추출하였지만, 천연물로부터 정유를 추출하는 방법 중 
에 성분파괴 없이 고순도 정유추출법인 초임계추출법으로 사용 하였다면, 더 좋은 항균효과가 있을 거라 예상되고, 추출방법별 항균효과의 비교도 앞으로 연구가 필요하다고 할 수 있다.

따라서, 본 연구의 결과로 다제내성 A. baumannii의 항균효 과를 입증하였고, 티트리가 항균효과가 좋았으며, 라벤더의 효 과는 미비하고, 로즈마리의 효과는 좋지 않음을 확인하였다. 향 후 천연 에센셜 오일을 이용한 손 소독제와 같은 항미생물 제재 로 활용이 가능할 것으로 사료된다.

\section{요 약}

Acinetobacter baumannii는 광범위한 항생제에 대한 저항 성으로 인해 감염된 환자의 사망률이 높아지는 적색 경보 병원 체로 분류됩니다. 이 연구에서 다제 내성 A. baumannii (MRAB)의 18 가지 임상 분리 균주에 대해 일부 에센셜 오일(티 트리, 로즈마리, 라벤더 오일)의 항균 활성을 평가하고자 하였 다. Carbapenemase 선별을 위한 Hodge 시험법은 A. baumannii 의 20 가지 균주가 모두 imipenem에 내성이 있음을 보여주었 습니다. 다제 내성 미생물의 확인은 VITEK 시스템을 통해 수행 하였다. 에센셜 오일의 항균 활성은 MRAB에 대한 디스크 확산 방법으로 평가하였다. 디스크 확산 방법에서 tee tree는 라벤더 오일에 비해 억제 크기가 가장 크게 증가했으며, 로즈마리는 항 균 효과가 없었다. 티 트리 오일은 가장 일반적인 인간 병원균 및 $\mathrm{MRAB}$ 감염의 치료 및 예방을 위한 대체 천연 제품으로 유용할 것으로 보인다. 따라서 이 연구의 결과는 다제 내성 $A$. baumannii의 항균 효과를 입증했으며, 미래에 천연 에센셜 오 일을 사용하는 손 소독제와 같은 항균제로 사용될 것으로 예상 됩니다.

Acknowledgements: 이 논문은 2018년도 원광보건대학교 교내연구비 지원에 의해서 수행됨.

Conflict of interest: None

Author's information (Position): Park $\mathrm{CE}^{1}$, Professor; Kwon PS ${ }^{2}$, Professor.

\section{REFERENCES}

1. De Rapper S, Kamatou G, Viljoen A, Van Vuuren S. The in vitro antimicrobial activity of lavandula angustifolia essential oil in combination with other aroma-therapeutic oils. Evid Based Complement Alternat Med. 2013;2013:852049. https://doi.org/10.1155/2013/852049.

2. Jalali-Heravi M1, Moazeni RS, Sereshti H. Analysis of iranian rosemary essential oil: application of gas chromatographymass spectrometry combined with chemometrics. J ChromatogrA. 2011;1218:2569-2576. https://doi.org/10.1016/j.chroma.2011. 02.048 .

3. Aruoma OI, Spencer JP, Rossi R, Aeschbach R, Khan A, Mahmood N, et al. An evaluation of the antioxidant and antiviral action of extracts of rosemary and Provençal herbs. Food Chem Toxicol. 1996;34:449-456.

4. Altinier G, Sosa S, Aquino RP, Mencherini T, Della Loggia R, Tubaro A. Characterization of topical antiinflammatory compounds in Rosmarinus officinalis L. J Agric Food Chem. 2007; 55:1718-1723.

5. Singletary K. MacDonald C. Wallig M. Inhibition by rosemary and carnosol of 7,12-dimethylbenz[a]anthracene (DMBA)-induced rat mammary tumorigenesis and in vivo DMBA-DNA adduct formation. Cancer Lett. 1996;104:43-48.

6. Richheimer SL. Bernart MW. King GA. Kent MC. Bailey DT. Antioxidant activity of lipid soluble phenolic diterpenes from rosemary. J Am Oil Chem Soc. 1996;73:507-514. https://doi.org/10.1007/BF02523927.

7. Hammer KA, Carson CF, Riley TV. In-vitro activity of essential oils, inparticular Melaleuca alternifolia (tea tree) oil and tea tree oil products against Candida spp. J Antimicrob Chemother. 1998;42:591-595.

8. Sadeghzadeh J, Vakili A, Bandegi AR, Sameni HR, Zahedi Khorasani M, Darabian M. Lavandula reduces heart injury via attenuating tumor necrosis factor-alpha and oxidative stress in a rat model of infarct-like myocardial injury. Cell J. 2017; 19:84-93.

9. Park YS. A meta-analysis of the effects of aromatherapy hand massage. Journal of Digital Convergence. 2015;13:469-479. https://doi.org/10.14400/JDC.2015.13.1.469.

10. Dijkshoorn L, Nemec A, Seifert H. An increasing threat in hospital: multidrug-resistant Acinetobacter baumannii. Nat Rev Microbiol. 2007;5:939-951.

11. Gales AC, Jones RN, Forward KR, Liñares J, Sader HS, Verhoef J. Emerging importance of multidrug-resistant Acinetobacter species and Stenotrophomonas maltophilia as pathogens in seriously ill patients: geographic patterns, epidemiological features, and trends in the SENTRY antimicrobial surveillance program (1997-1999). Clin Infect Dis. 2001;32:104-113.

12. Chong $Y$, Lee K. Present situation of antimicrobial resistance in Korea. J Infect Chemother. 2000;6:189-195.

13. Kwon KT, Oh WS, Song JH, Chang HH, Jung SI, Kim SW, et al. Impact of imipenem resistance on mortality in patients with Acinetobacter bacteraemia. J Antimicrob Chemother. 2007;59: 525-530. https://doi.org/10.1093/jac/dkl499.

14. Lee Y, Kim YA, Song W, Lee H, Lee HS, Jang SJ, et al. Recent trends in antimicrobial resistance in intensive care units in Korea. Korean J Nosocomial Infect Control. 2014;19:29-36. https://doi.org/10.14192/kjnic.2014.19.1.29.

15. Korea Centers for Disease Control and Prevention. (Infection control guidelines for multidrug resistant microorganisms in healthcare facilities 2012 [Internet]. Cheongju: Korean Centers for Disease Control and Prevention; 2012 [cited 2018 Oct 01]. Available from:http://www.cdc.go.kr/CDC/together/CdcKrTogether 0302.jsp?menuIds=HOME006-MNU2804-MNU3027-MNU2979\& 
cid $=138310$.

16. Clinical Laboratory Standards Institute. Methods for dilution antimicrobial susceptibility tests for bacteria that grow aerobically; Approved standard-12th ed, M07-A10. Wayne, PA: Clinical Laboratory Standards Institute; 2015. p27-47.

17. Clinical Laboratory Standards Institute. Performance standards for antimicrobial susceptibility testing; Approved standard 26th ed, M100-S22. Wayne, PA: Clinical Laboratory Standards Institute; 2015. p170-180.

18. Kubo I, Muroi H, Kubo A. Structural functions of antimicrobial long-chain alcohols and phenols. Bioorg Med Chem. 1995; 3:873-880. https://doi.org/10.1016/0968-0896(95) 00081-Q.

19. Sakanaka S, Juneja LR, Taniguchi M. Antimicrobial effects of green tea polyphenols on thermophilic sporeforming bacteria. J Biosci Bioeng. 2000;90:81-85.

20. Cho MH, Bae EK, Ha SD, Park JY. Application of natural antimicrobials to food industry. Food Sci Inds. 2005;38:36-45.

21. Lee JH, Lee SR. Some physiological activity of phenolic substances in plant foods. Korean J Food Sci Technol. 1994;26: 317-323.

22. Topisirovic L, Kojic M, Fira D, Golic N, Strahinic I, Lozo J. Potential of lactic acid bacteria isolated from specific natural niches in food production and preservation. Int $\mathrm{J}$ Food
Microbiol. 2006;112:230-235.

23. Shin YH, Kim HJ, Lee JY, Cho YJ, An BJ. Major compound analysis and assessment of natural essential oil on anti-oxidative and anti-microbial effects. J Life Sci 2012;22:1344-1351.

24. Sienkiewicz M, Łysakowska M, Ciećwierz J, Denys P, Kowalczyk E. Antibacterial activity of thyme and lavender essential oils. Med Chem. 2011;7:674-689.

25. Mohaddese M, Nastaran K, Mohsen T. The antibacterial activity of some essential oils against clinical isolates of Acinetobacter baumannii. Songklanakarin J Sci Technol. 2014;36:513-519.

26. Nguefack J, Budde BB, Jakobsen M. Five essential oils from aromatic plants of Cameroon: their antibactetial activity and ability to permeabilize the cytoplasmic membrane of Listeria innocua examined by flow cytometry. Lett Appl Microbiol. 2004;39:395-400. https://doi.org/10.1111/j.1472-765X.2004. 01587.x.

27. Bouhdid S, Abrinin J, Zhiri A, Espuny MJ, Munresa A. Investigation of functional and morphological changes in Pseudomonas aeruginosa and staphylococcus aureus cells induced by Origanum compactum essential oil. J Appl Microbiol. 2009;106:1558-1568. https://doi.org/10.1111/j.1365-2672. 2008.04124.x. 